\title{
As fontes de energia e algumas inter-relações CTS concebidas por licenciandos da área de Ciências Naturais ${ }^{+*}$
}

Tiago Clarimundo Ramos ${ }^{1}$

Instituto Federal Goiano - Campus Rio Verde

Rio Verde - GO

Marcos Fernandes-Sobrinho ${ }^{l}$

Instituto Federal Goiano - Campus Urutaí

Urutaí - GO

\section{Resumo}

A ficção do crescimento ilimitado em um planeta finito tem se mostrado insustentável. Nesse sentido, torna-se relevante que sejam acordadas ações conjuntas de controle mais efetivo das atividades econômicas, especialmente para evitar degradação ainda maior da biosfera. É diante dessa problemática e à luz de aportes da educação Ciência-TecnologiaSociedade (CTS) que, neste estudo, dispõe-se a responder como licenciandos da área de Ciências Naturais concebem a questão da exploração de diferentes fontes na matriz energética. Em consonância com esse questionamento, objetiva-se analisar os conhecimentos sobre fontes de energia, bem como as inter-relações CTS concebidas por um grupo de 16 sujeitos participantes da pesquisa. Além de identificar certo desconhecimento por parte dos licenciandos em relação à participação das fontes de energia em diferentes matrizes (nacionais e mundiais), com necessidade de esclarecimentos a respeito de determinados fenômenos básicos (como chuva ácida), constatou-se um predomínio de concepções de inter-relações CTS que endossam os mitos da superioridade do modelo de decisões tecnocráticas, da perspectiva salvacionista/redentora atribuída à Ciência e Tecnologia, do determinismo tecnológico e do crescimento econômico ilimitado. Espera-se que este estudo sirva para desper-

\footnotetext{
${ }^{+}$Energy sources and some STS interrelations conceived by Natural Science area's undergraduates

* Recebido: maio de 2018. Aceito: novembro de 2018.

1 E-mails: tiago.ramos@ifgoiano.edu.br; marcos.fernandes@ifgoiano.edu.br
} 
tar educadores, sobretudo da área de Ciências Naturais, a fim de minimizarem essas lacunas na formação de professores.

Palavras-chave: Fontes de Energia; Inter-relações CTS; Educação CTS; Formação de Professores.

\begin{abstract}
The fiction of uncontrolled growth in a finite planet has proven itself as unsustainable. In this regard, it becomes relevant that joint actions for more effective control of economic activities be agreed on, especially to avoid further deterioration of the biosphere. It is in the face of this issue and in light of STS (Science-Technology-Society) education's input that, on this study, there will be answered how undergraduates from Natural Science area comprehend the exploration of different sources in energetic matrix. In accord with this questioning the objective ends up being to analyze the information about energy sources as well as STS interrelation conceived by a team of 16 participants of the survey. Besides recognizing a specific unfamiliarity with respect to the undergraduates concerning the energy source's feature in different matrixes (both national and worldwide speaking), with the need of enlightenment in respect of particular basic phenomena such as acid rain, could be observed a predominance of conceptions about STS interrelation that endorse the superiority myths of the technocratic decisions model, the salvationist/redemptorist perspective attributed to Science and Technology, the technologic determinism and the unlimited economic growth. This study is expected to be a revival for educators, especially on the Natural Science area, in order to minimize these gaps on professor's qualification.
\end{abstract}

Keywords: Energy Sources; STS Interrelations; STS Education; Formation of Professors.

\title{
I. Introdução
}

Não há dúvidas de que o uso de determinadas fontes em uma matriz energética combina variados fatores, que vão desde disponibilidades de recursos e preços a preocupações com o crescimento econômico, políticas de Governo, de Estado, leis ambientais e qualidade de vida. Paralelamente, entretanto, há claros indícios de uma estrutura nociva que tem sido engendrada na sociedade sob duplo signo de dependência e dominação: de um lado, tem-se 
uma dependência em relação à oferta de energia para atender às demandas da sociedade; de outro, uma dominação sob o aspecto financeiro, comercial e tecnológico de grandes corporações que forçam a caracterização do consumo a seus próprios interesses (PAIVA, 2012).

Assim como alertam Mattozo e Camargo (2005), os modelos copiados dos países industrializados destoam muito da realidade interna e, geralmente, têm originado políticas inadequadas às reais condições e demandas sociais.

Nos últimos anos, começaram a surgir, no Brasil e no mundo, algumas reivindicações em prol de fontes de energia menos poluentes, de transporte coletivo, entre outros (REIS; FADIGAS; CARVALHO, 2012); todavia, até o momento, tais posturas [proativas] são bastante pontuais.

Se nada for feito, contudo, para conter o atual modelo de crescimento econômico, certamente haverá degradação ainda maior da biosfera, além de acentuar os conflitos pela exploração das últimas possibilidades de não incorporação de externalidades no uso dos bens gratuitos (ou baratos) que restam (LÉNA, 2012).

Diante dessa problemática e à luz de aportes da educação Ciência-TecnologiaSociedade (CTS), dispõe-se com esta investigação responder ao seguinte questionamento: como os licenciandos da área de Ciências Naturais concebem a questão da exploração de diferentes fontes na matriz energética? Em consonância com esse questionamento, objetiva-se analisar tanto os conhecimentos sobre as fontes de energia como as inter-relações CTS $^{2}$ concebidas pelos participantes da pesquisa.

Nesse trabalho, a perspectiva crítica de educação CTS encontra-se firmada em aportes freirianos (AULER, 2011) e no Pensamento Latino-americano em Ciência-TecnologiaSociedade (PLACTS), frente a uma responsabilidade maior de defender a instauração de novos modelos de ciência, de tecnologia e de sociedade (VARSAVSKY, 1969; HERRERA, 1973), quer sejam mais democráticos e comprometidos socioambientalmente. De igual modo, entram em cena outros referenciais, dos quais Georgescu-Roegen (1971) é precursor, com indicação de limites termodinâmicos ao crescimento econômico.

\section{Pressupostos teóricos}

Particularmente no Pós-Segunda Guerra Mundial, especificamente no período que se prolongou ao longo do século passado, a humanidade passou a tomar conhecimento de uma série de problemas sociais, econômicos e ambientais associados ao desenvolvimento científico e tecnológico (SANTOS, 2011).

É nesse cenário que surgiu o movimento CTS como uma crítica ao modelo linear de progresso apregoado, sobretudo, no Hemisfério Norte (particularmente, Estados Unidos e

\footnotetext{
${ }^{2}$ As concepç̃̃es de inter-relações CTS remetem às ideias manifestas pelos sujeitos na apreciação de questões que, em certa medida, comportam distintas articulações entre Ciência, Tecnologia e Sociedade no contexto da temática matriz energética.
} 
Europa), de que desenvolvimento científico (DC) gera desenvolvimento tecnológico (DT) e desenvolvimento econômico (DE) que, inexoravelmente, conduz ao desenvolvimento social (DS - bem-estar social).

Conforme acentuam González-García, López-Cerezo e Luján-López (1996), os estudos em CTS têm em comum: (I) o rechaço à imagem de ciência como atividade pura e neutra; (II) a crítica à concepção de tecnologia como ciência aplicada e neutra; e (III) a promoção da participação pública na tomada de decisão.

Auler e Delizoicov (2001) indicam, por sua vez, que existem duas perspectivas bem distintas que permeiam CTS no ensino de Ciências. De um lado, a apropriação reducionista é aquela que não considera elementos subjacentes à construção de conhecimentos científicos e tecnológicos, reforçando uma concepção de neutralidade da ciência e tecnologia (CT) que conduz aos mitos da superioridade do modelo de decisões tecnocráticas ${ }^{3}$, da perspectiva salvacionista da $\mathrm{CT}^{4}$ e do determinismo tecnológico ${ }^{5}$. Essas construções, consideradas pouco consistentes, são entendidas como pilares da suposta neutralidade da CT que realimentam um modelo linear de progresso, em que se apregoa um desenvolvimento científico (DC) que, por sua vez, implica o bem-estar social, passando pelo desenvolvimento tecnológico (DT) e econômico (DE). Por outro lado, a apropriação ampliada é aquela que intenta compreender as inter-relações CTS mediante a problematização e superação desses mitos.

Ademais, neste estudo, cabe considerar que a ficção de crescer infinitamente em um planeta finito não se sustenta (LÉNA, 2012; CECHIN, 2010). A aposta no crescimento ilimitado é por demais utópica, mormente em razão da existência de limites entrópicos ${ }^{6}$ sinalizados na segunda lei da termodinâmica clássica. De fato, assim como reportado desde GeorgescuRoegen (1971), não há, em nosso planeta, recursos suficientes para atender um crescimento generalizado na demanda e oferta energética, visto que comporta processos irreversíveis com elevada degradação de energia.

\footnotetext{
${ }^{3}$ Cada dia mais tem se verificado a consolidação de uma tecnociência que, nas imposições do neoliberalismo às instituições que a produzem e financiam, levam à sua crescente mercantilização. É nesse horizonte que ocorrem as tomadas de decisões pela tecnocracia visando, sobretudo, reforçar a ideia de que somente o expert (especialista/técnico) pode solucionar os problemas, inclusive os sociais, de um modo eficiente e neutro.

${ }^{4}$ Na perspectiva salvacionista da CT, apregoa-se que o desenvolvimento da CT certamente conduzirá à solução dos problemas existentes e ao bem-estar social, porém, desconsidera que para além de uma medida técnica, o enfrentamento dos problemas devem requerer soluções políticas.

${ }^{5}$ Com base no determinismo tecnológico, a tecnologia é entendida como totalmente autônoma e independente das influências sociais, além de ser o principal fator que gera a mudança social.

${ }^{6}$ A entropia é um conceito crucial no estudo do aproveitamento da energia. É uma propriedade que está diretamente relacionada à segunda lei da termodinâmica. A variação na entropia depende apenas dos estados inicial e final do sistema. Para um sistema fechado, sempre que temos um processo irreversível, a entropia aumenta. Pode-se dizer que todos os mecanismos de produção de energia "organizada" com aumento de desordem implicam aumento na entropia do sistema. O próprio aumento da poluição provocada pela queima dos combustíveis, por exemplo, pode ser entendido como evidência clara de passagem de um estado de menor para outro de maior grau de desordem; em suma, caracterizado pelo aumento da entropia do sistema. Nesse sentido, conforme realça Carvalho (2009), admite-se que os diversos fenômenos e intervenções produzidas na Terra têm contribuído para aumentar a entropia do Universo, tornando nossa energia cada vez menos utilizável.
} 
É desejável que, no contexto atual, se invista mais em pesquisa tecnológica para melhorar a eficiência energética e ampliar a adoção de fontes não fósseis. Mas isso não pode escamotear o fato de que a humanidade precisa começar a se preocupar em reverter o curso de intensificação contínua das atividades econômicas, vez que não haverá matriz energética que garanta a voracidade por energia consoante a esse modelo. Por isso, julga-se tão importante que a questão da exploração de diferentes fontes na matriz energética seja discutida no âmbito da educação CTS sempre com rejeição a qualquer solução tecnocientífica milagrosa (AULER; DELIZOICOV, 2001). Por mais que seja importante estabelecer uma nova matriz energética, no sentido de explorar novas tecnologias e outras fontes renováveis menos poluentes (BRASIL, 2007), deve-se admitir que essa saída tem suas limitações.

Auler (2011, p. 92) destaca que reduzir o papel da educação científica à apropriação da cultura implica apropriar-se de uma "cultura que é consumista (pano de fundo à degradação socioambiental), de valores consumistas, de valores tecnocráticos, alicerces da sociedade industrial capitalista, ou seja, sua reprodução".

De acordo com Varsavsky (1969, p. 20, tradução própria),

[...] nossa ciência é moldada por nosso próprio sistema social. Suas regras, suas classificações, suas elites podem ser questionadas; estas existem não por direito divino ou lei da natureza, mas por adaptação da sociedade atual, e podem estar completamente inadequadas para sociedade futura.

Particularmente na América Latina, conforme sublinha Herrera (1973), houve completo fracasso nas tentativas de incrementar sua capacidade científica e tecnológica na superação de seus atrasos sociais por meio de parcerias com organismos internacionais. Grande parte dos centros de pesquisa tem estreita ligação com as grandes potências internacionais, tanto com relação às temáticas de investigação como, em muitos casos, por causa da origem de seus fundos de fomento. Com isso, falta correspondência entre objetivos de pesquisa frente aos problemas regionais básicos que faz acentuar ainda mais o carácter distintivo de subdesenvolvimento. Assim, tal atraso científico e tecnológico, como se apresenta, não é simplesmente resultado de uma carência de parcerias, mas é consequência de toda uma estrutura econômica e social.

O sistema de valores dos economistas tem como elementos fundamentais a crença de que a tecnologia tem a capacidade de substituir insumos e serviços da natureza por insumos e capital construídos (CECHIN, 2010). Nesse sentido, porém, a ideia por detrás da soberania do consumidor se orienta pela redução de quaisquer valores a uma unidade monetária comensurável.

Conforme adverte Cechin (2010, p. 201):

Tudo estará bem e ocorrendo de maneira sustentável se os indivíduos do futuro consumirem a mesma, ou maior, quantidade de bens e serviços que a geração atual, 
mesmo que tenham de respirar um ar poluído, suportar temperaturas mais elevadas e sobreviver com uma variedade menor de alimentos.

No entendimento de Léna (2012), contudo, resta pouco tempo para reverter o atual modelo de desenvolvimento e isso requer profundas mudanças na sociedade; haja vista que o metabolismo da humanidade, marcado pela destruição de ecossistemas e biodiversidade, consumo de matérias-primas renováveis e não-renováveis, produção de lixo e poluição, tem atingido dimensões alarmantes e chega a por em risco sua própria existência, ao menos na forma com que se concebe a civilização.

Posto isso, reafirma-se que, neste estudo, a perspectiva crítica de educação CTS ultrapassa a rejeição à Ciência e Tecnologia (CT) em si, mas demanda reflexões mais profundas por parte do sujeito sobre sua condição no mundo frente à $\mathrm{CT}$, muitas vezes postas a serviço de interesses particulares, do crescimento econômico, consumismo e seus mecanismos de degradação social e ambiental, que comprometem a qualidade de vida das gerações de hoje e do futuro.

\section{Aspectos metodológicos}

Este estudo comporta a análise de um questionário, com itens em escala Likert de cinco níveis, aplicado no contraturno a 16 licenciandos bolsistas de um subprojeto do Programa Institucional de Bolsa de Iniciação à Docência (Pibid) de Química, em uma instituição da Rede Federal de Educação Profissional e Tecnológica, da Região Centro-Oeste.

Esses sujeitos estavam, em sua maioria, bem avançados no curso de Licenciatura em Química, sendo que apenas uma licencianda era reingressa do primeiro ano com aproveitamento de algumas disciplinas. Dois cursavam segundo ano; cinco o terceiro ano; e oito estavam no quarto [e último] ano. No que tange à faixa etária, apenas dois bolsistas tinham menos de 20 anos; os demais estavam com idade entre 20 e 30 anos. Assim como nove licenciandos se dedicavam exclusivamente ao curso; cinco já atuavam como professores de Química na educação básica; e outros dois trabalhavam em outras áreas profissionais.

Embora este trabalho seja parte de uma investigação mais ampla, no campo da formação de professores da área de Ciências Naturais, é necessário pontuar que antes de aplicar o questionário não houve nenhum tipo de discussão e (ou) estudo prévio que pudesse, de certo modo, auxiliar os licenciandos a responderem as questões propostas. Somente após a aplicação do questionário foram planejados outros encontros com encaminhamentos teóricos e práticos em relação às fontes de energia, matriz energética e Educação CTS. Todavia, os achados das análises dos seminários, discussão em grupo e debate realizados compõem o escopo de outras publicações.

No conjunto, o questionário contemplou seis perguntas que vão desde a participação das fontes de energia em diferentes matrizes aos impactos ambientais de processos de produção e consumo e às tomadas de decisão. 
1. Indique os três principais fatores responsáveis pela crise energética no Brasil e no mundo.

2. Qual fonte de energia você julga ser a mais utilizada na (2a) matriz energética brasileira? (2b) matriz energética mundial? (2c) geração de energia elétrica brasileira? (2d) geração de energia elétrica mundial?

3. Para as próximas décadas, qual(is) fonte(s) de energia você SUSPEITA que será(ão) utilizada(s) mais intensamente na matriz energética brasileira?

4. Para as próximas décadas, qual(is) fonte(s) de energia você REALMENTE GOSTARIA que fosse $(\mathrm{m})$ utilizada(s) mais intensamente na matriz energética brasileira? (4a) Petróleo. (4b) Carvão mineral. (4c) Gás natural. (4d) Nuclear. (4e) Hidráulica. (4f) Cana-deaçúcar e derivados. (4g) Outras fontes renováveis. Justifique.

5. Em sua opinião, os processos de produção e consumo energético têm relação com (5a) chuva ácida? (5b) mudança climática global?

6. Em sua opinião, os pesquisadores que atuam no campo da energia (6a) são as pessoas mais indicadas para tomarem decisões a respeito da matriz energética, porque detém conhecimento especializado. (6b) são responsáveis pela produção de novos conhecimentos científicos que, por sua vez, geram novas tecnologias que resolvem problemas da sociedade. (6c) estão preocupados com todos os efeitos de suas descobertas, porque o objetivo de seus estudos é tornar o mundo um lugar melhor para se viver.

Todos os 16 licenciandos participantes desta pesquisa assinaram um Termo de Consentimento Livre e Esclarecido. Em atendimento aos preceitos éticos, na exposição dos dados gerados na pesquisa, as 11 moças e cinco moços participantes serão citados por seus pseudônimos: Ana, Artur, Atena, Augusto, Aurora, Elina, Isaque, Karen, Lara, Leonel, Lilian, Marisa, Morgana, Ramon, Rita e Sabrina.

Destaca-se ainda que toda a análise das concepções de inter-relações CTS norteia-se pelos aportes indicados na seção anterior e sintetizados pelas categorias de endosso ou superação: da superioridade do modelo de decisões tecnocráticas, da perspectiva salvacionista/redentora atribuída à CT, do determinismo tecnológico (AULER; DELIZOICOV, 2001) e do crescimento econômico ilimitado (GEORGESCU-ROEGEN, 1971). É pertinente reafirmar que, neste estudo, as concepções de inter-relações CTS dizem respeito às compreensões evidenciadas em posicionamentos dos licenciandos nas questões relacionadas à matriz energética e que, em determinada medida, comportaram distintas articulações entre Ciência, Tecnologia e Sociedade.

\section{Resultados e discussão}

Os resultados das análises, nas seções seguintes, focalizam tanto os conhecimentos sobre as fontes de energia como as inter-relações CTS concebidas pelos licenciandos. 


\section{IV.1 Análise das respostas à questão 1}

Conforme indicado na Fig. 1, sobressaíram três principais fatores responsáveis pela crise energética no Brasil e no mundo: falta de desenvolvimento de novas tecnologias, política de governo e crescimento da população. Na indicação do fator outro, houve uma menção à falta de exploração em larga escala das energias renováveis, que também remete à falta de desenvolvimento de novas tecnologias.

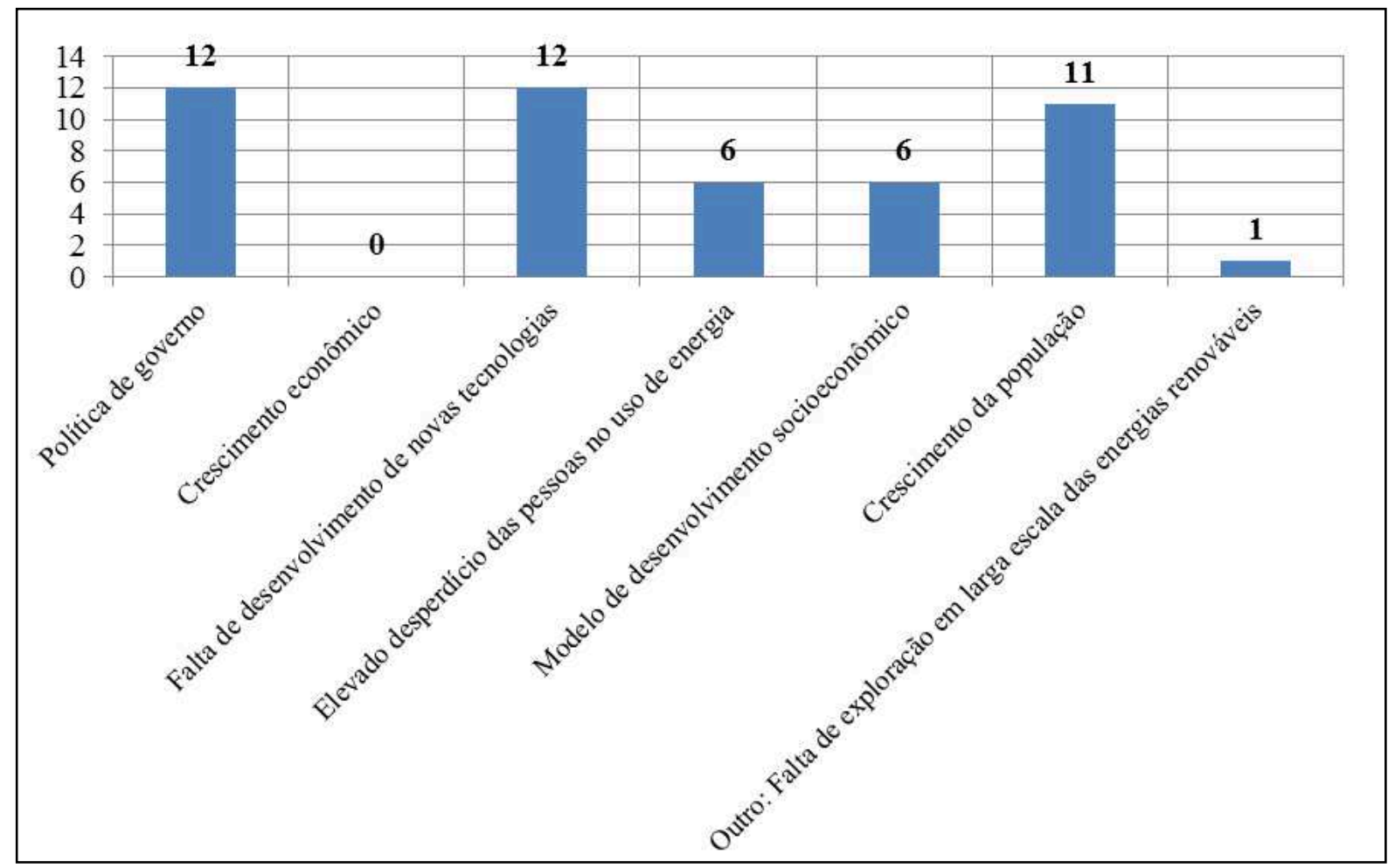

Fig. 1 - Frequência de respostas na questão 1.

A falta de desenvolvimento tecnológico demonstrou ser o fator mais relevante, em convergência com concepções de inter-relações CTS que endossam uma perspectiva salvacionista/redentora atribuída à CT. Além disso, a ausência de indicação ao fator crescimento econômico também sinaliza concepções de inter-relações CTS pautadas pelo ceticismo a limites entrópicos para o crescimento econômico ilimitado (GEORGESCU-ROEGEN, 1971; CECHIN, 2010; LÉNA, 2012). As tímidas indicações ao elevado desperdício das pessoas no uso de energia e ao modelo de desenvolvimento socioeconômico levam a inferir também certo endosso ao consumismo/obsolescência/descarte de produtos que perpassa um crescimento econômico ilimitado. 


\section{IV.2 Análise das respostas à questão 2}

Com respeito a conhecimentos sobre matriz energética brasileira (BRASIL, 2007), assim como mostrado na Fig. 2, poucos reconheceram que a fonte mais utilizada era petróleo; ao passo que a maioria acertou tanto o protagonismo dessa fonte na matriz energética mundial quanto o predomínio da fonte hidráulica na geração de energia elétrica brasileira. Somente um participante confirmou que carvão mineral é a fonte mais recorrente, no cenário mundial, para geração de energia elétrica. Alguns participantes chegaram, inclusive, a apontar que o carvão mineral era uma fonte ultrapassada ou em desuso, assim como se apresenta posteriormente em justificativas ao item $4 b$.

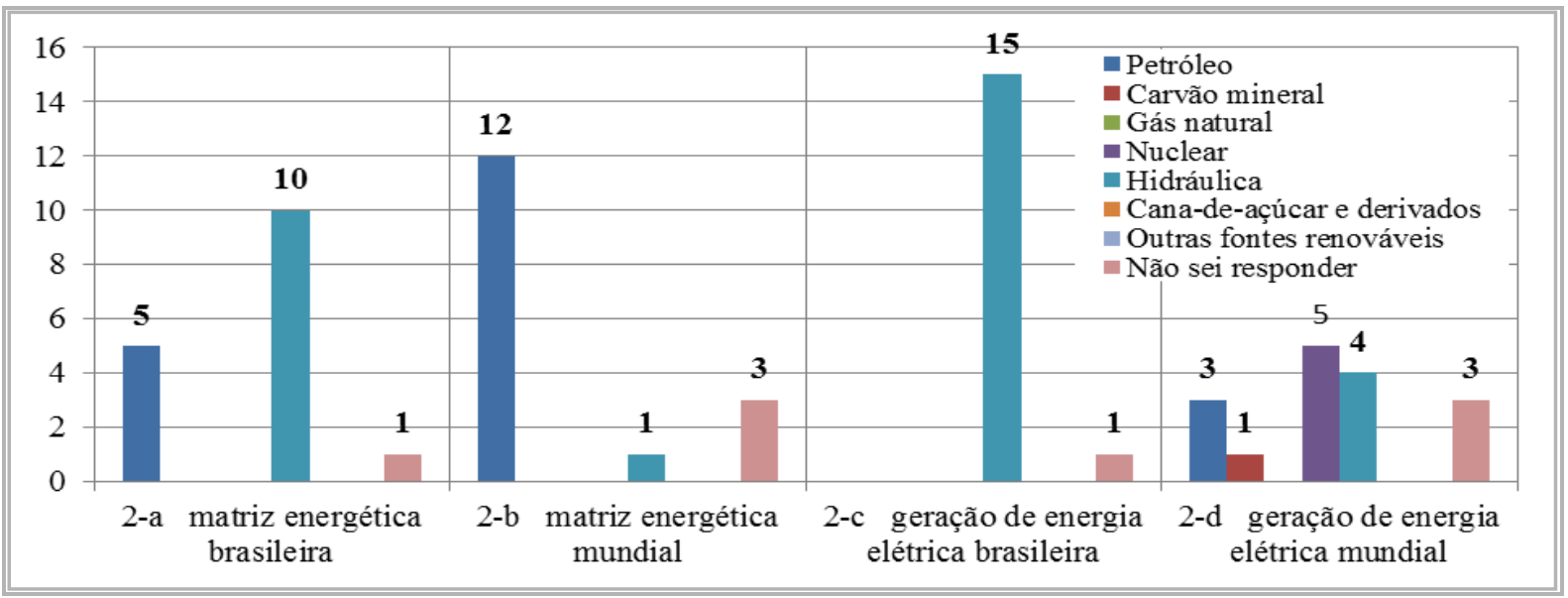

Fig. 2 - Frequência de respostas na questão 2.

\section{IV.3 Análise das respostas à questão 3}

Conforme ilustrado Fig. 3, ao serem questionados sobre qual(is) fonte(s) de energia os licenciandos suspeitavam que será(ão) utilizada(s) mais intensamente na matriz energética brasileira nas próximas décadas, poucos indicaram petróleo. Metade dos participantes presumiu que carvão mineral não terá seu uso intensificado; outra metade ficou di stribuída entre alguns que não souberam responder e outros que apontaram seu uso mais intenso.

Com respeito ao gás natural e nuclear, houve certo equilíbrio na distribuição daqueles que suspeitaram ou não de um uso mais intenso. Grande parte suspeitou que haverá intensificação no uso da fonte hidráulica, cana-de-açúcar e outras fontes renováveis. Esses resultados sinalizam certo ceticismo a limites entrópicos para o crescimento econômico (GEORGESCU-ROEGEN, 1971; CECHIN, 2010; LÉNA, 2012); vez que na ótica desses sujeitos a elevação na demanda energética certamente pode ser atendida por uma matriz nacional mais renovável. 


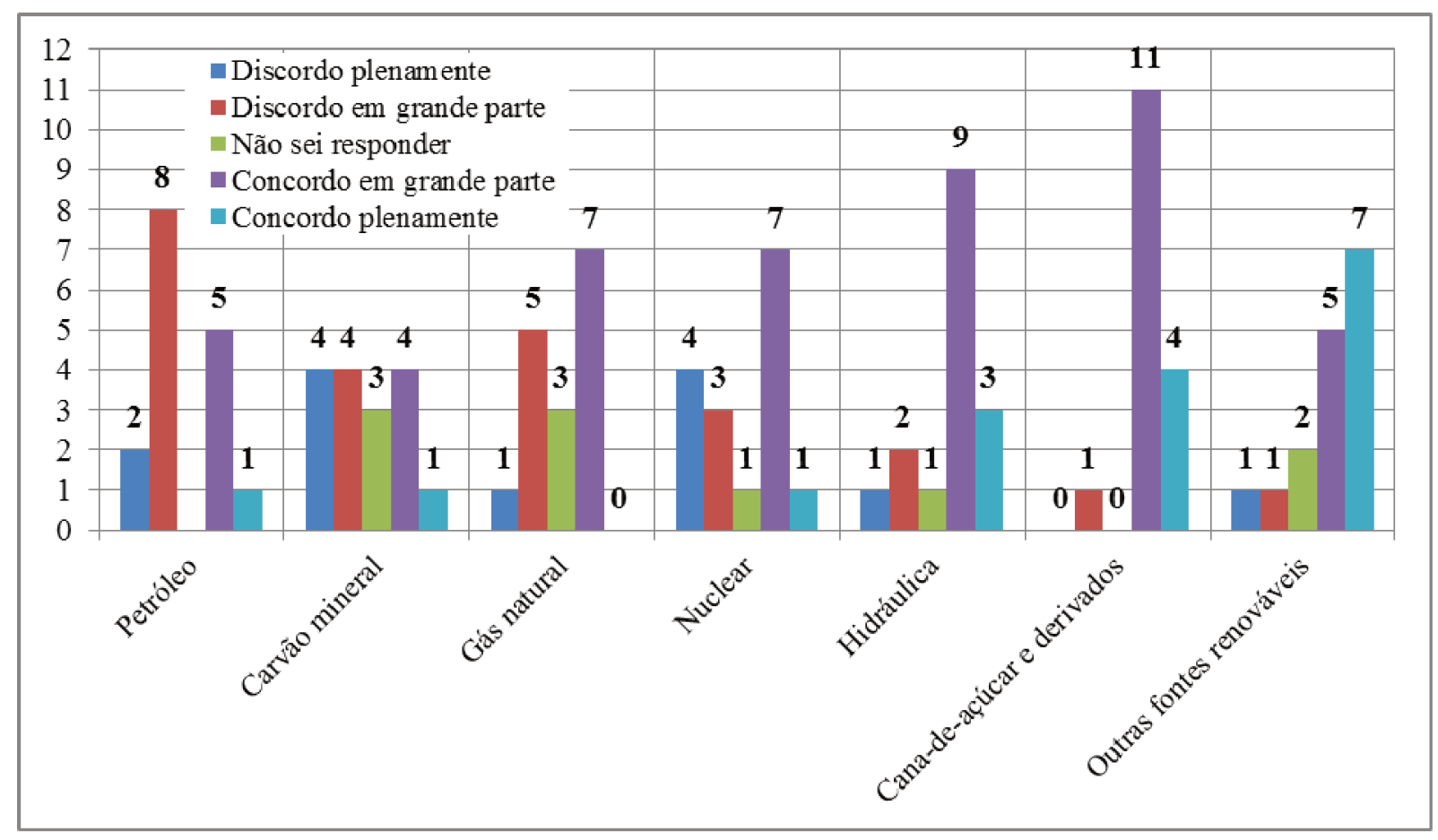

Fig. 3 - Frequência de respostas na questão 3.

\section{IV.4 Análise das respostas à questão 4}

$\mathrm{Na}$ análise das respostas dos licenciandos ao questionamento sobre qual(is) fonte(s) de energia realmente gostariam que fosse(m) utilizada(s) mais intensamente na matriz energética brasileira nas próximas décadas, comparando com as respostas do questionamento anterior, houve ampliação no número daqueles que discordaram de petróleo, carvão mineral, gás natural e nuclear. Além disso, conforme indicado na Fig. 4, manteve-se uma aprovação, da maioria, pela exploração mais intensa de fonte hidráulica, cana-de-açúcar e, principalmente, no caso de outras fontes renováveis (como eólica e solar). Assim, foram constatados novos indícios de ceticismo dos licenciandos em relação aos limites entrópicos para o crescimento econômico (GEORGESCU-ROEGEN, 1971; CECHIN, 2010; LÉNA, 2012).

Nas alíneas a seguir, são aprofundadas as análises das concepções de inter-relações CTS manifestas em justificativas à intensificação de uso de diferentes fontes de energia.

\section{IV.4.1 Justificativas ao petróleo}

As discordâncias de uso mais intenso de petróleo foram, geralmente, acompanhadas de justificativas que guardavam relação com concepções de inter-relações CTS de reconhecimento de limites entrópicos (GEORGESCU-ROEGEN, 1971; CECHIN, 2010; LÉNA, 2012); e (ou) com avaliação/consideração de riscos/prejuízos em prol de vantagens/benefícios. 


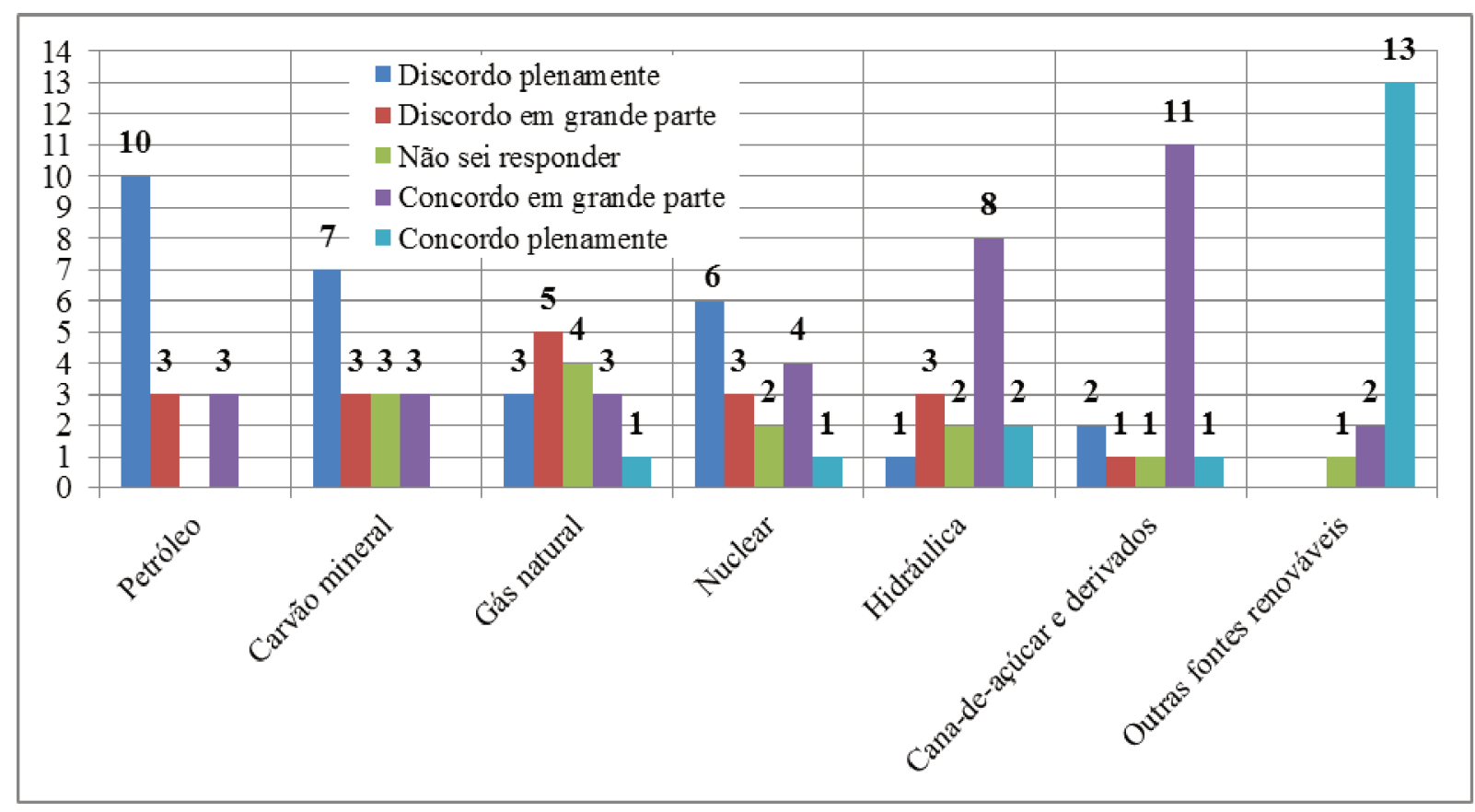

Fig. 4-Frequência de respostas na questão 4.

Em uma das discordâncias plenas, Elina alegou que "não terá petróleo suficiente para gerar energia para o consumo de toda a população". Ramon justificou que "a queima do petróleo causa poluição". Semelhantemente, a oposição de Lilian se deu "por causa da poluição e por ser uma fonte esgotável". Na justificativa de Ana, "com o aumento do uso de petróleo, a utilização do mesmo poderá acarretar a escassez, vindo a aumentar ainda mais os seus valores". Assim como para Rita, "sua utilização não é renovável, sendo uma fonte esgotável de energia, além de danificar o planeta". Cabe realçar, porém, que apenas Karen sublinhou prejuízos aos seres humanos: "o uso do petróleo causa muitos danos à natureza e às pesso$a s^{\prime \prime}$.

Por outro lado, apenas alguns apresentaram concordâncias em grande parte, acompanhadas de justificativas fundamentadas em concepções de inter-relações CTS de endosso ao consumismo; e (ou) de aceitação/desconsideração de riscos e prejuízos em prol de vantagens e desvantagens. Para Marisa: "o petróleo é muito importante e devemos sim utilizá-lo. O paralelo que faço está relacionado à má utilização desta rica fonte de energia." Assim como justificou Artur: "pelo fato de ser uma fonte não-renovável, é grande poluente, mas ainda é grande fonte de energia". Tais alegações acerca da queima de petróleo se mostram bastante reducionistas, sobretudo pelos graves problemas vinculados ao ciclo de carbono (LÉNA, 2012).

\section{IV.4.2 Justificativas ao carvão mineral}

Entre aqueles que discordaram da intensificação no uso de carvão mineral, sobressaíram concepções de inter-relações CTS que ora guardavam relação com reconhecimento de 
limites entrópicos (GEORGESCU-ROEGEN, 1971; CECHIN, 2010; LÉNA, 2012); outrora com avaliação/consideração de riscos/prejuízos em prol de vantagens/benefícios. Na discordância plena de Rita, por exemplo, carvão mineral "é uma fonte esgotável". Enquanto para Karen, "o descarte de resíduos, os perigos da mineração e os impactos ambientais desfavorecem o uso do carvão mineral". Em outra justificativa, "devido ao desmatamento", ressalta-se que Ana demonstrou claro equívoco ao considerar carvão mineral como carvão vegetal. Ao discordar em grande parte, Atena justificou que "ele já vem sendo substituído"; uma afirmação errônea, vez que, segundo histórico da matriz nacional nos últimos 30 anos, a pequena redução no percentual para carvão mineral pode ser traduzida, em termos absolutos, em considerável aumento na oferta dessa fonte. Semelhantemente, no entendimento de Leonel, "não se utiliza mais como fonte de energia". Para Sabrina, "é um recurso antigo e por certo não será mais utilizado".

Entre aqueles que concordaram em grande parte, também comportaram justificativas nas categorias de reconhecimento de limites entrópicos (GEORGESCU-ROEGEN, 1971; CECHIN, 2010; LÉNA, 2012) e (ou) de aceitação/desconsideração de riscos/prejuízos em prol de vantagens/benefícios. No entendimento de Isaque, "por enquanto ainda é encontrado em maior quantidade". Enquanto para Ramon, "já foi mais usado antigamente, mas creio que a escassez de carvão mineral causa diminuição na produção desse tipo de energia".

\section{IV.4.3 Justificativas ao gás natural}

As justificativas de discordância com a intensificação no uso de gás natural foram permeadas por concepções de inter-relações CTS centradas na avaliação/consideração de riscos/prejuízos em prol de vantagens/benefícios. Karen, por exemplo, ao discordar plenamente asseverou que "os riscos de asfixia, explosão e o fato de não ser renovável implicam na rejeição do uso do mesmo". Assim como a rejeição de Lilian foi "por causa da poluição e esgotamento". Ao passo que Isaque justificou sua discordância em grande parte "pelos gases poluentes, fumaça tóxica e problemas na camada de ozônio".

Já as concordâncias comportaram justificativas de concepções de inter-relações CTS pautadas pelo determinismo tecnológico, sinalizando aceitação de uma tecnologia autônoma e independente das influências sociais; e (ou) pelo ceticismo a limites entrópicos (GEORGESCU-ROEGEN, 1971; CECHIN, 2010; LÉNA, 2012). Conforme pontuou Artur, tratava-se de uma "fonte em crescimento". Assim como Marisa justificou que "é essencial para todos nós".

\section{IV.4.4 Justificativas à fonte nuclear}

Entre as justificativas de discordância sobressaíram concepções de inter-relações CTS centradas na avaliação/consideração de riscos/prejuízos em prol de vantagens/benefícios. Em discordância plena, Leonel justificou que "trata-se de uma energia que gera muito resíduo radioativo que não pode ser reaproveitado". Assim como para Atena, "a energia nuclear 
é prejudicial à saúde humana". Já Artur, ao discordar em grande parte, salientou que "qualquer acidente pode ser muito prejudicial ao meio ambiente". Enquanto Sabrina pontuou: "É uma fonte de energia bastante rentável. No entanto, bastante perigosa. Acredito que o Brasil possui outras alternativas de matriz energética." Observe que essa justificativa acentua a substituição da energia nuclear por outras fontes sem verdadeiramente preconizar uma redução no consumo.

De outro lado, as justificativas para concordância remeteram ao ceticismo a limites entrópicos (GEORGESCU-ROEGEN, 1971; CECHIN, 2010; LÉNA, 2012) e (ou) à aceitação/desconsideração de riscos/prejuízos em prol de vantagens/benefícios. Ao concordar em grande parte, Marisa justificou que "a energia nuclear é uma rica fonte de energia". Enquanto Augusto, em sua concordância plena, pontuou que "essa fonte deve ser mais utilizada devido às novas tecnologias, custos e porque se usada corretamente gera pequenos impactos".

\section{IV.4.5 Justificativas à fonte hidráulica}

Entre os poucos que discordaram, surgiram alegações pautadas no reconhecimento de limites entrópicos (GEORGESCU-ROEGEN, 1971; CECHIN, 2010; LÉNA, 2012) e (ou) na avaliação/consideração de riscos/prejuízos em prol de vantagens/benefícios. Na justificativa de discordância plena de Atena, por exemplo, "a falta de água já é um problema atual". Isaque, por sua vez, ao discordar em grande parte, ponderou: "não temos água o suficiente". Assim como Rita justificou sua avaliação "pelo fato de que para sua implantação, grandes áreas verdes devem ser inundadas, levando a uma grande produção e liberação de $\mathrm{CO}_{2}$, liberação esta que se repete a cada vez que a represa passa por cheia".

Mesmo com ressalvas, a maioria declarou concordar com a intensificação no uso de fonte hidráulica, predominando em suas justificativas concepções de inter-relações CTS que se alternaram entre ceticismo a limites entrópicos, reconhecimento de limites entrópicos (GEORGESCU-ROEGEN, 1971; CECHIN, 2010; LÉNA, 2012) e (ou) aceitação/desconsideração de riscos/prejuízos em prol de vantagens/benefícios. Sabrina justificou, por exemplo, concordância plena "devido ao potencial hídrico do país". Ramon, por sua vez, relativizou: "por mais que a produção desse tipo de energia não seja propícia para a fauna e a flora, ainda acho que é um tipo de produção menos poluente ao meio ambiente". Algo semelhante se manifestou nas justificativas daqueles que concordaram em grande parte. Segundo Karen, "apesar das grandes alterações ambientais, a fonte hidráulica está entre uma das mais favoráveis". Assim como ponderou Morgana: "Não concordo tanto devido à problemática da falta de água que estamos passando. Não sei se teríamos barragens e água suficientes e se não prejudicaria ainda mais esta questão."

\section{IV.4.6 Justificativas à cana-de-açúcar}

Apenas alguns licenciandos discordaram da intensificação no uso de cana-de-açúcar, pautando suas justificativas em concepções de inter-relações CTS, com avalia- 
ção/consideração de riscos/prejuízos em prol de vantagens/benefícios. Conforme justificou Ramon, "sua queima causa poluição". Da mesma forma que para Elina, "isso acabaria com a terra de tanto plantar e replantar cana".

A maioria declarou concordar com a intensificação no uso de cana-de-açúcar e derivados, prevalecendo em suas justificativas concepções de inter-relações CTS de que o avanço tecnológico não opera por si mesmo e comporta influências sociais e (ou) de aceitação/desconsideração de riscos/benefícios em prol de vantagens/benefícios. Sabrina, por exemplo, concordou plenamente por tratar-se de "uma fonte energética que vem crescendo bastante e recebendo apoio político". Enquanto ao concordar em grande parte, Augusto justificou que "o etanol é biocombustível, fonte renovável não tão cara e pouco poluente". Rita, por sua vez, fez ressalvas: "é uma fonte renovável de energia, fazendo desta uma boa opção, mas também tem uma série de pontos negativos que não fazem tão bem ao meio ambiente". Segundo Leonel: "É uma energia limpa, que além de produzir energia, gera derivados reaproveitáveis. É eficiente, mas demanda grande quantidade de água para irrigação." Assim como Isaque consentiu que "apesar da erosão e impacto ambiental que a cana causa, essa energia de qualquer forma precisa ser produzida pelas usinas".

\section{IV.4.7 Justificativas a outras fontes renováveis}

No bojo de todas as fontes, o maior consenso, em termos de concordância, foi constatado para outras fontes renováveis (principalmente, eólica e solar). De maneira que ninguém se manifestou contrário. Assim como em suas justificativas foram constatadas concepções de inter-relações CTS, segundo uma perspectiva salvacionista/redentora atribuída à CT, de que desenvolvimento cada vez maior de CT conduzirá, em algum momento, à solução de problemas hoje existentes e ao bem-estar social; de que a inovação tecnológica aparece como o fator principal da mudança social; de ceticismo a limites entrópicos (GEORGESCU-ROEGEN, 1971; CECHIN, 2010; LÉNA, 2012); de endosso ao consumismo/obsolescência/descarte de produtos; e (ou) de aceitação/desconsideração de riscos/prejuízos em prol de vantagens/benefícios.

Atena, por exemplo, considerou: "Devido à preocupação com a utilização das atuais fontes de energia esgotáveis, creio que outras fontes surgirão para substituir as atuais". Assim como Sabrina fez a seguinte explicação: "Vem crescendo a pesquisa e tecnologia em energias renováveis, por isso serão bastante utilizadas". Ana, por sua vez, realçou que "a energia solar seria adequada a país de clima tropical". Ao passo que Rita, mesmo com ressalvas, fez sua apreciação: "Energia solar e eólica podem ser excelentes fontes de geração de energia elétrica. Tem seus contras também, mas seus prós são mais eficientes." Nesse sentido, parece que a solução ao esgotamento de fontes não-renováveis depende somente de empenho de pesquisadores para viabilização de novas tecnologias de energia, ditas eficientes e inesgotáveis, para serem utilizadas na sociedade. Lara acrescentou que "é necessário investir em pesquisa, e atualmente, o governo está abrindo caminhos para essa área". Karen, por sua 
vez, endossou: "Acredito que o lixo que produzimos diariamente é bem capaz de devolver a nós a energia que gastamos com ele". Já Aurora, ao concordar em grande parte, justificou que "energia eólica é uma das fontes que mais crescem; e, o Brasil é um dos países de grande potencial eólico". Enquanto segundo Isaque, "é preciso desenvolver formas mais econômicas e sem acabar com a natureza". Essa alegação, porém, é por demais contraditória, mormente por tentar, ao mesmo tempo, compatibilizar um aumento no consumo com minimização da degradação do planeta.

\section{IV.5 Análise das respostas à questão 5}

De acordo com resultados apresentados na Fig. 5, observe que a maioria dos licenciandos discordou ou não soube responder se havia qualquer relação entre chuva ácida e processos de produção e consumo energético. Isso pode sugerir certo desconhecimento por parte desses sujeitos sobre em que consiste o fenômeno chuva ácida. A concordância praticamente unânime no que tange à relação desses processos com a mudança climática global conduz ao entendimento de que, em grande medida, os licenciandos aderem mais à corrente que concorda com influências de ações antropogênicas na mudança climática global.

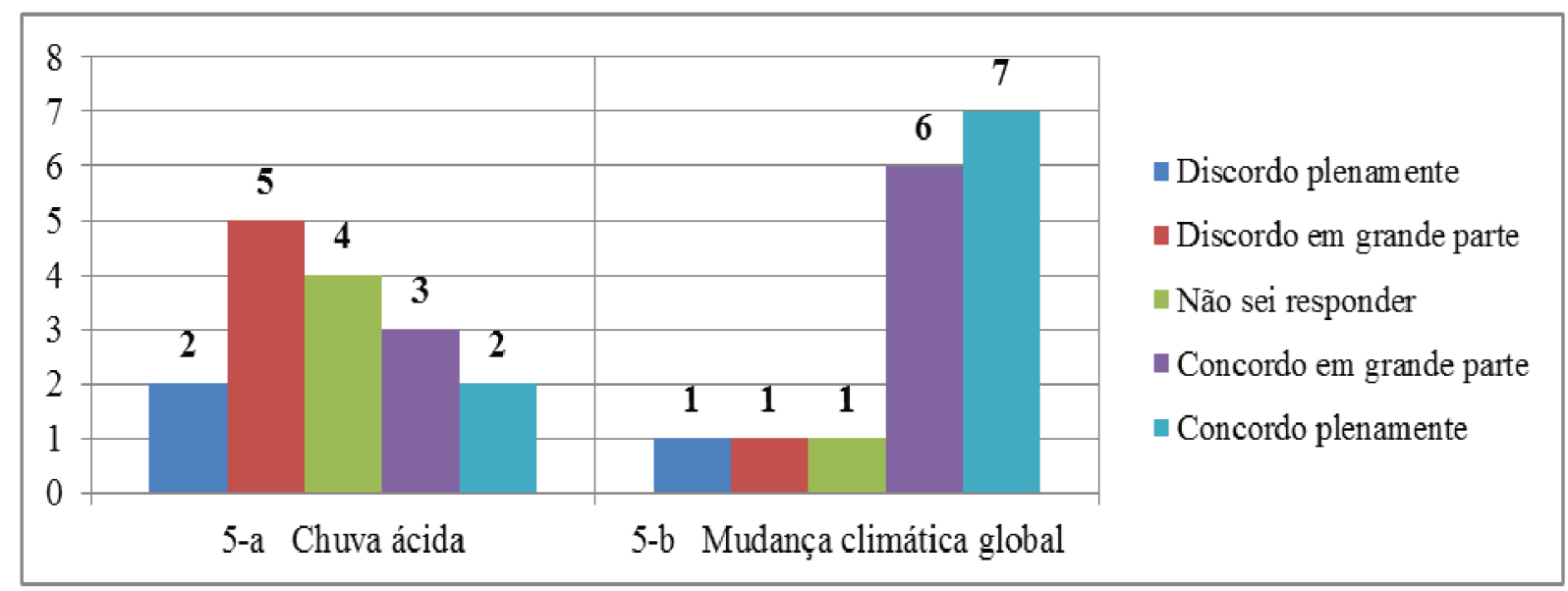

Fig. 5 - Frequência de respostas na questão 5.

Importa destacar que, até o momento, a questão relativa às causas do aquecimento global é polêmica e não está resolvida no campo da ciência. Enquanto alguns alegam que o homem tem impactado na elevação da temperatura do planeta; outros se mostram céticos às causas antropogênicas do aquecimento global. Entretanto, independente de qual seja a interpretação para o fenômeno da mudança climática, é necessário defender que, pelos próprios limites entrópicos (GEORGESCU-ROEGEN, 1971; CECHIN, 2010; LÉNA, 2012), se tenha um maior comprometimento em controlar as atividades econômicas, principalmente, para garantir uma sobrevivência humana mais digna para as gerações futuras. 


\section{IV.6 Análise das respostas à questão 6}

Assim como mostrado na Fig. 6, quase todos concordaram com a afirmação de que os pesquisadores que atuam no campo da energia são as pessoas mais indicadas para tomarem decisões a respeito da matriz energética, porque detém conhecimento especializado. Isso conduz, porém, a concepções de inter-relações CTS que respaldam a superioridade do modelo de decisões tecnocráticas, tanto em termos da neutralização do sujeito no proces so científico; do endosso de que o expert (especialista/técnico) pode solucionar os problemas, inclusive os sociais, de um modo eficiente e neutro; quanto pela eliminação de conflitos ideológicos ou de interesse.

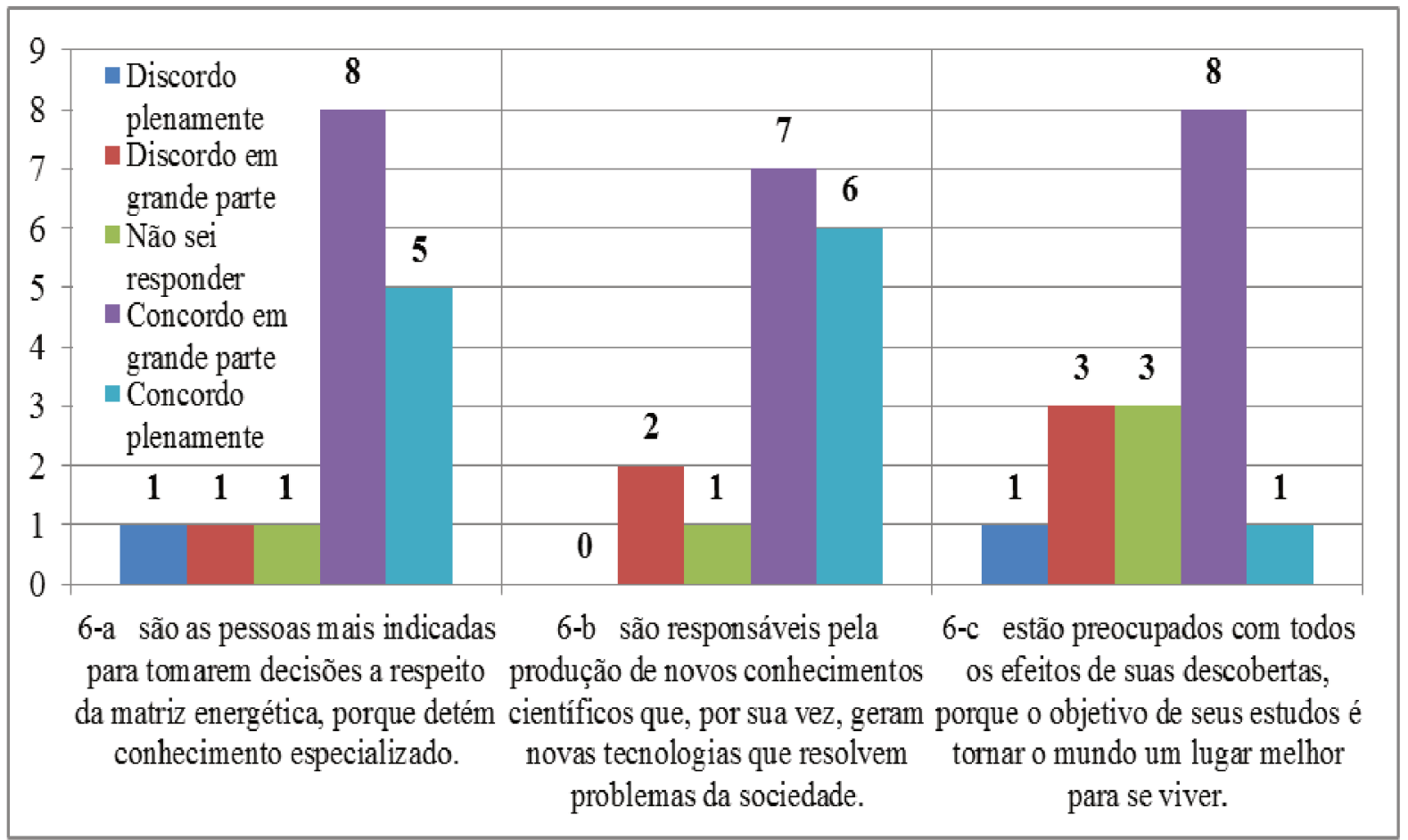

Fig. 6 - Frequência de respostas na questão 6.

A forte concordância com a alegação de que a produção de novos conhecimentos científicos gera novas tecnologias que resolvem problemas da sociedade apontou concepções de inter-relações CTS que endossam um modelo linear de progresso; no qual os problemas sociais são remetidos apenas ao campo técnico. Semelhantemente, a maioria dos licenciandos reforçou um modelo linear de progresso, ao concordar com a afirmação de que os pesquisadores que atuam no campo da energia estão preocupados com todos os efeitos de suas descobertas, porque o objetivo de seus estudos é tornar o mundo um lugar melhor para se viver. 


\section{Considerações finais}

Mediante as análises das respostas aos itens do questionário, além de identificar certo desconhecimento por parte dos licenciandos em relação à participação das fontes de energia em diferentes matrizes (nacionais e mundiais), com necessidade de esclarecimentos a respeito de determinados fenômenos básicos (como chuva ácida), constatou-se um predomínio de concepções de inter-relações CTS que endossam os mitos da superioridade do modelo de decisões tecnocráticas, da perspectiva salvacionista/redentora atribuída à $\mathrm{CT}$, do determinismo tecnológico e do crescimento econômico ilimitado (AULER; DELIZOICOV, 2001; GEORGESCU-ROEGEN, 1971).

Em relação à superioridade do modelo de decisões tecnocráticas, prevaleceram concepções de inter-relações CTS pautadas pela neutralização/eliminação do sujeito do processo científico e tecnológico; pela aceitação de que o expert (especialista/técnico) pode solucionar todos os problemas, inclusive os sociais, de um modo eficiente e neutro; e pela eliminação de conflitos ideológicos ou de interesse.

No que tange à perspectiva salvacionista/redentora atribuída à CT, emergiram concepções de inter-relações CTS que endossam o discurso de que o desenvolvimento cada vez maior da CT conduzirá, em algum momento, à solução de problemas hoje existentes e ao bem-estar social; e além de remeter os problemas sociais ao campo técnico.

A concepção de superação ao determinismo tecnológico emergiu apenas de uma única justificativa para incentivos políticos à cana-de-açúcar e derivados, com sinalização de que o avanço tecnológico não opera por si mesmo e comporta influências sociais (VARSAVSKY, 1969; HERRERA, 1973). Por outro lado, foram identificadas outras justificativas concorrentes apoiadas em concepções de endosso ao determinismo tecnológico, de que as energias renováveis deverão ser bastante utilizadas em razão do desenvolvimento da pesquisa tecnológica nessa área. Nesse caso, a inovação tecnológica apareceu como fator principal da mudança no comportamento social.

Igualmente apareceram outras justificativas em concordância com a intensificação no uso de gás natural, com indícios de uma tecnologia autônoma que independe de influências sociais, simplesmente por ser uma opção que está em ascensão.

Ao questionar os licenciandos sobre quais fontes gostariam que fossem mais utilizadas, emergiram concepções de inter-relações CTS voltadas, sobretudo, à avaliação/consideração de riscos/prejuízos em prol de vantagens/benefícios. No entanto, em diversas justificativas, não houve objeção alguma à problemática do consumo desenfreado; nem se manifestou preocupação com a qualidade de vida das gerações de hoje e (ou) do futuro (LÉNA, 2012). Predominou, principalmente, propostas de substituição de fontes não-renováveis por outras renováveis.

Além da ausência de uma rejeição ao consumismo/obsolescência/descarte de produtos; e da falta de preocupação com as gerações de hoje e (ou) do futuro; em alguns casos, mesmo reconhecendo limites entrópicos, foram manifestas concepções de inter-relações CTS 
vinculadas à aceitação/desconsideração de riscos/prejuízos em prol de vantagens/benefícios. Isso ficou bastante explícito, por exemplo, quando Morgana concordou em grande parte com a intensificação no uso de fonte hidráulica, mesmo com a afirmação de que reconhecia problemas oriundos da escassez hídrica. Nesse sentido, parece que algo deixou de ser ruim, simplesmente pela expectativa de algum benefício momentâneo. Além disso, alguns licenciandos apesar de reconhecerem que o avanço tecnológico não opera por si mesmo e comporta influências sociais, acabaram demonstrando certo ceticismo aos limites entrópicos (GEORGESCU-ROEGEN, 1971; CECHIN, 2010; LÉNA, 2012) com endosso ao consumismo.

É inadmissível, porém, continuar com uma intensificação das atividades produtivas para atender à acumulação do capital, especialmente em razão da lógica consumista elevar [e muito] a geração de resíduos poluentes que são lançados no ambiente. Ao apoderar-se de enorme quantidade de energia, principalmente pela queima de combustíveis fósseis, constatase que o homem tem provocado acelerada degradação dos recursos naturais, acompanhada de excessiva liberação de carbono para a atmosfera e outros graves distúrbios biogeoquímicos que alteram a vida na Terra (LÉNA, 2012).

Até então só temos conseguido manter o referido crescimento econômico às custas da exploração de recursos de baixa entropia (como o petróleo e carvão mineral), que tem possibilitado contrabalancear o aumento de entropia que ela ocasiona. Outrossim, reafirma-se que a segunda lei da termodinâmica permanece válida (CECHIN, 2010); e isso já pode ser percebido tanto pela perda da biodiversidade quanto pelo aumento no número de catástrofes naturais.

Nesse contexto, os combustíveis fósseis são realmente os recursos naturais extraídos de reservas geológicas que melhor corporificam os problemas do ciclo de carbono. Diante disso, importa defender sim a criação e aplicação de mecanismos pelos quais a expansão dos sistemas e a escolha das diferentes opções energéticas não priorizem apenas os custos financeiros, passando a considerar também outros critérios relacionados às repercussões socioambientais provocadas pela produção e consumo dessas fontes.

Contudo, mesmo que passemos a usar apenas os biocombustíveis e outras fontes energéticas renováveis, se não houver mudanças nos atuais modelos científicos, tecnológicos e sociais, ainda assim, não se resolverá a questão da elevada degradação socioambiental. Por isso, sugere-se a necessidade de comprometimento de todos com uma nova agenda de pesquisa científica e tecnológica, que seja mais apropriada à realidade da grande maioria da sociedade (VARSAVSKY, 1969; HERRERA, 1973). Essa pode ser a saída mais profícua não somente no sentido de buscar reduzir os desperdícios e o descarte de materiais em geral, mas, principalmente, para gerar a tão almejada reestruturação dos nossos padrões de produção, de consumo, de urbanização, de transportes etc.

Para finalizar, aponta-se que é bem preocupante o fato de que os participantes desta pesquisa tenham manifestado uma confiança maior em medidas técnicas do que na adoção de soluções políticas dos problemas. Tanto é que nenhum deles assinalou o fator crescimento 
econômico como responsável pela crise energética. Poucos sujeitos atentaram-se ao desperdício de energia e ao modelo de desenvolvimento socioeconômico; assim como constataram-se fortes indícios de endosso dos licenciandos à ideia de se continuar balizando a obsessão por um modelo crescente de oferta de energia que não é sustentável (GEORGESCU-ROEGEN, 1971). Destarte, espera-se que o presente estudo sirva para despertar educadores, sobretudo da área de Ciências Naturais, a fim de empreenderem ações que visem à minimização dessas lacunas na formação de professores.

\section{Referências}

AULER, D. Novos caminhos para a educação CTS: ampliando a participação. In: SANTOS, W. L. P.; AULER, D. CTS e educação científica: desafios, tendências e resultados de pesquisas. Brasília: Editora UnB, 2011, p. 73-97.

AULER, D.; DELIZOICOV, D. Alfabetização científico-tecnológica para quê? Ensaio, v. 3, n. 1, p. 1-13, 2001.

BRASIL. Ministério de Minas e Energia (MME) \& Empresa de Pesquisa Energética (EPE). Matriz Energética Nacional 2030. Brasília: MME: EPE, 2007.

CARVALHO, J. F. O declínio da era do petróleo e a transição da matriz energética brasileira para um modelo sustentável. 2009. 146 f. Tese (Doutorado em Energia) - Instituto de Energia e Ambiente, USP, São Paulo.

CECHIN, A. A natureza como limite da economia: a contribuição de Nicholas GeorgescuRoegen. São Paulo: Editora Senac, 2010.

DAGNINO, R. Neutralidade da ciência e determinismo tecnológico: um debate sobre a tecnociência. Campinas: Unicamp, 2008.

GEORGESCU-ROEGEN, N. The Entropy law and the economic process. Cambridge: Harvard University Press, 1971.

GONZÁLEZ-GARCÍA, M. I.; LÓPEZ-CEREZO, J. A.; LUJÁN-LÓPEZ, J. L. Ciencia, tecnologia y sociedade: una introducción al estúdio social de la ciência y la tecnologia. Madrid: Editorial Tecnos, 1996.

HERRERA, A. O. Los determinantes sociales de la política científica en América Latina: política científica explícita y política científica implícita. Revista de Ciências Sociais, v. 13, n. 49, p. 98-112, 1973.

LÉNA, P. Os limites do crescimento econômico e a busca pela sustentabilidade: uma introdução ao debate. In: LÉNA, P.; NASCIMENTO, E. P. (Orgs.). Enfrentando os limites do cres- 
cimento: sustentabilidade, decrescimento e prosperidade. Rio de Janeiro: Garamond, 2012, p. 23-43.

MATTOZO, V.; CAMARGO, C. C. B. Energia, ambiente e mídia: qual é a questão? 1. ed. Florianópolis: Editora UFSC, 2005.

PAIVA, R. U. P. Petróleo e a Física: uma visão contextualizada para o ensino médio. 2012. 102 f. Dissertação (Mestrado em Ensino de Ciências e Matemática) - Puc Minas, Belo Horizonte.

REIS, L. B.; FADIGAS, E. A. F. A.; CARVALHO, C. E. Energia, Recursos Naturais e a Prática do Desenvolvimento Sustentável. 2. ed. Barueri: Manole, 2012.

SANTOS, W. L. P. Significados da educação científica com enfoque CTS. In: SANTOS, W. L. P.; AULER, D. (Orgs.). CTS e educação científica: desafios, tendências e resultados de pesquisa. Brasília: Editora UnB, 2011, p. 21-47.

VARSAVSKY, O. Ciencia, política y cientificismo. Buenos Aires: Centro Editor de América Latina, 1969. 